\title{
Relationship between Lumbar and Ischiotibial Flexibility in Pentathletes from Escuela Militar de Cadetes "General José María Córdova" in Bogotá D.C., Colombia
}

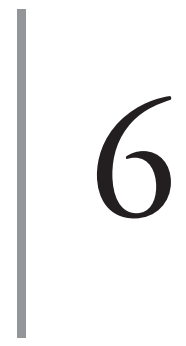

https://doi.org/10.21830/9789585380240.06

\author{
Diego Fabricio Rodriguez Camacho ${ }^{1}$ \\ Juan Felipe Correa Mesa ${ }^{2}$
}

\begin{abstract}
Flexibility is a critical physical component in sports performance. It must be trained, planned, and quantified to improve the range of motion of joints. Therefore, measuring the posterior muscle chain longitudinally, emphasizing the ischotybial and low lumbar areas, has become common-use in clinical practice. Assessment is conducted by using the sit and reach test, which has become a preferred element for sports-related professionals because of its easy application and high relative intra-examiner reliability $(0.89-0.99)$. Given that the posterior chain involves a postural component and the trunk's posterior region, a single test for this chain can produce a false positive, considering that this chain is complemented in the lower limb from the hip joint. On account of the aforementioned, this research sought to examine the relationship among the results of applying the sit and reach, Schober, and passive straight leg raise tests (PSLR) in pentathletes from Escuela Militar de Cadetes "General José María Córdova" in Bogotá, Colombia. This descriptive study of association and transectional design set out to determine the relationship among the results of applying these tests at a given time
\end{abstract}

1 Physiotherapist. Master's in Sport and Physical Activity Physiotherapy. Military Physical Performance Research Group, RENFIMIL, Escuela Militar de Cadetes "General José María Córdova”

2 Physiotherapist. Master's in Sport and Physical Activity Physiotherapy. 
in a convenience sampling of seven participants. Based on the sample measured in this study, there is no relationship among the flexibility tests, except for the sit and reach test and left leg flexibility, which have a negative correlation. Thus, characterization of flexibility requires several complementary measures to analyze and justify dysfunctions in the posterior chain.

Keywords: muscle flexibility, sport, range of motion, hamstring muscles

\section{Introduction}

Flexibility is a determining physical trait in sports performance. Like strength, power, and endurance, it must be trained in planned and quantified spaces to improve the range of joint movement (1). The literature includes reports on the benefits of flexibility work, including, thermal changes in the connective tissue, pain reduction, and injury prevention. It is even the favored strategy in various sports for activation and returning to calm. However, these benefits are currently being debated. Diverse positions exist concerning the understanding of the concept. Thus, the extrinsic and intrinsic characteristics that influence the joint motion range and the therapeutic strategies used to improve such have become unclear $(1,2)$.

In everyday life, concepts of flexibility and stretching are used synonymously. It should be clarified that flexibility refers to an individual's characteristic intrinsic factors that involve various intra- and extra-articular components (bones, cartilage, ligaments, muscles, tendons, fascia, and skin). Stretching is a modifiable extrinsic factor commonly involved in warming up and cooling down in sports; it is also involved in injury prevention and improving an athlete's performance (3).

However, stretching should be addressed within the topic of flexibility. Stretching generates acute effects called viscoelastic effects. They are associated with changes in the range of motion and resistance to stretching related to changes in stress relaxation, creep, and tissue hysteresis, as well as neural effects resulting from decreased motor neuron excitability rates. As a magnet effect, they produce relaxation and a decreased ability to produce power during a sporting activity, despite generating a temporary lengthening of the muscle $(3,4)$. 
Considering that muscle injury is cited as the most frequent in sports practice, different positions also exist regarding the benefits of stretching. Epidemiological studies have reported that decreased flexibility is a risk factor for acute muscle injury; therefore, it should be trained as a protective element (5). Some in vitro studies have been used to argue the changes in myotendinous viscoelasticity because of excessive temperature increase in the muscle prior to activity, which decreases the muscle's ability to absorb energy and may result in injury. Although the information found differs among authors, it is necessary to specify the modality that corresponds to each response (5).

Based on the previously stated, the literature shows that the most referred variants of stretching are static and dynamic, which report different effects. For example, in static stretching, the movement's eccentric phase is mainly affected by a change in the lengthening-cutting cycle in which the elastic recoil and rigidity of the myotendinous junction are decreased. The latter is necessary for storage of elastic energy. The result obtained, added to the inhibition of the motor neurons by depression of the H-reflex, is the decrease in the stretched muscle's ability to produce power; this also favors the antagonist muscle's imbalance because of reciprocal inhibition (4).

Authors, like Alikhajeh et al., also mention that decreased performance due to passive stretching occurs because said stretching increases compliance of the muscle-tendon unit that reduces its stiffness, reducing the development of strength. Moreover, this response produces neural inhibition and decreased neural impulses to the muscle, ultimately resulting in reduced power production (4).

Other studies have found that static stretching has negative implications in performing activities that require power, such as jumping, where evidence exists of a $4.4 \%$ to $7 \%$ decrease in height for drop jumping, $4.3 \%$ to $4 \%$ in squat jumps, and a $9.5 \%$ decrease in maximum voluntary contraction force. However, the parameters and techniques used to approach flexibility are unclear. Therefore, its justification remains controversial (6). 
In contrast, dynamic stretching before activity produces an increase in the central temperature. The movements involved prepare and stimulate coordination of movement patterns associated with the sports gesture; in turn, the nerve receptors' sensitivity is increased, boosting the nerve impulse's speed, thus, generating faster and more efficient muscle contractions that provide important inputs to adopt simple and complex postures, typical of sports (4). Considering that athletes are exposed to musculoskeletal injuries from the moment they are exposed to sports, this stretching can provide preventive benefits (7).

Because flexibility requires complex coordination between connective tissue structures, understood as a conditional physical quality, it must be stimulated through a planned process with specific objectives. For instance, Ayala et al., reported improved hip range motion after a 12-week program of active stretching three times per week with daily doses of 180 seconds in people with and without hamstring retraction (8). However, to identify flexibility training's true impact through stretching, it is indispensable to use the right measurement tools to ensure corrective therapeutic strategies in professional practice.

Thus, measuring flexibility as a conditional physical quality is fundamental to identify risk factors that influence the sports gesture within the different processes of sports characterization and pre-participation assessments. Accordingly, in clinical practice, the longitudinal measurement of the posterior muscle chain, emphasizing the ischiotibial and lower lumbar area, is often included by using the sit and reach test. This test's easy application and high relative intra-examiner reliability (0.89-0.99) have made it a preferential element for professionals involved in sports $(9,10)$.

Although the sit and reach test has moderate mean validity to estimate ischiotibial flexibility ( $\mathrm{rp}=0.46-0.67)$ and low mean to estimate lumbar flexibility ( $\mathrm{rp}=0.16-0.35)(11)$, in professional practice, confusion can arise regarding the test's yield of low quantitative results, produced by the involvement of the postural component and stimulation of the trunk's posterior muscular chain. A limitation of this chain can produce a false positive based 
on the examinees' difficulty in positioning themselves and executing the test, considering that this chain is complemented in the lower limb from the hip joint (12).

An objective and quantitative discrimination of which component of the chain presents the dysfunction will also likely be necessary to more accurately assess such with the least possible bias. This is indispensable for the prescription of stretching to improve flexibility in athletes and the general population. Different tests are reported in the literature that can corroborate the results obtained in the sit and reach test. The Schober test measures mobility in the lumbar spine, for example (13), and the PSLR or the 90:90 test measure ischiotibial elasticity from knee flexion at $90^{\circ}$ to full extension (14).

Accordingly, the aim of this research was to estimate the relationship among the results of applying the sit and reach test, the Schober test, and the PSLR tests in pentathletes from Escuela Militar de Cadetes "General José María Córdova" (ESMIC) in Bogotá, Colombia.

\section{Methods}

This descriptive study of association and transectional design sought to determine the relationship among the results of applying the sit and reach test, the Schober test, and the PSLR tests at a given time in pentathletes from ESMIC in Bogotá, Colombia. The convenience sampling included seven participants. The inclusion criteria were male subjects in the pentathlon selection process at ESMIC, complying with the informed consent provided by the researcher. The exclusion criteria considered all those factors that could bias the tests' results, such as individuals presenting musculoskeletal lesions in the dorsolumbar area and the lower limbs that would make it difficult to adopt the position and perform the tests, and those practicing another sport in parallel to pentathlon.

The Schober test was used to measure the lumbar spine's flexibility according to the protocol established in the literature (13). The PSLR test 
was used to measure ischiotibial elasticity, following the criteria developed for its correct execution (14). The standard sit and reach test was used to measure the joints at the lumbar and ischiotibial levels, following the necessary considerations and requirements for its correct application described in the literature $(8,11)$.

The data analysis initially involved processing the descriptive results by using the $\mathrm{R}$ program version 3.6.0. The information was placed in tables and the average and standard deviation were calculated for each variable. Pearson's linear correlation coefficient was used for the variables' correlation analysis to statistically identify the degree of relationship between two variables measured at an interval level (15).

The ethical considerations were based on the Colombian Ministry of Health's Resolution No. 008430 of 1993, Article 11, which classifies this study as minimum risk, where routine and common procedures do not involve manipulating the subjects' conduct (16). The ethical principles of the Helsinki Declaration for medical research involving human subjects were also considered (17).

\section{Results}

Application of the tests showed that for lumbar flexion, the subjects obtained an average value of $4.14 \mathrm{~cm}$ with a standard deviation (SD) of 0.87 , indicating that most of the sample was within the normal range, except for one subject who only achieved $2.5 \mathrm{~cm}$ of flexion. For lumbar extension, all subjects were below the normal parameters, with an average of $1.21 \mathrm{~cm}$ and SD of 0.58 .

When measuring ischiotibial elasticity, it was observed that, with the exception of two subjects, the sample showed moderate-to-severe muscular shortening, considering that the literature accepts a knee flexion angle of $20^{\circ}$ starting from $90^{\circ}$ as a limit value. The average result was similar in the right and left extremities with averages of $33.1^{\circ}$ and $33.3^{\circ}$, respectively. However, the $\mathrm{SD}$ value provides evidence of result variabilities among the subjects, finding angles of up to $50^{\circ}$. 
Finally, the average result of $9.91 \mathrm{~cm}$ was found when applying the sit and reach test. This value is below the minimum accepted range. According to the American College of Sports Medicine's classification, all the subjects would require flexibility training. Moreover, one test subject obtained a value of $0 \mathrm{~cm}$ during the test, producing an SD of 5.60 .

The data correlation analysis was also performed by using Pearson's linear correlation coefficient to measure the degree of relationship between the Schober test and the sit and reach test, and the PSLR test with the sit and reach test.

According to the analysis performed between the variables, the result to determine the degree of association between the Schober and sit and reach tests was very weak. This result allows inferring that no association existed between the lumbar flexion-extension range of motion measured with a tape measure and the lumbar flexion measured in conjunction with the ischiotibial group.

Although the hypothesis tests for the correlations' statistical significance were performed using $t=r \sqrt{n}-2 / \sqrt{1}-r^{2}$, which was distributed as a Student's $\mathrm{t}$ with $\mathrm{n}-2$ degrees of freedom under the non-correlation hypothesis, the correlation between sit and reach and Schober bending, the $\mathrm{p}$ value was 0.5552. This result shows that the null hypothesis cannot be rejected and, therefore, there is no statistical association between these two variables.

The same hypothesis test was performed to observe if the correlation between the sit and reach and Schober's tests during the extension measurement was significant, obtaining a p value of 0.9655 ; this does not allow rejecting the hypothesis of no association.

A significant negative linear association between the PSLR and the sit and reach test relationship analysis was found through hamstring elasticity measurement. This indicates that when the subjects obtain a higher result in the sit and reach test, the PSLR test result will be lower in terms of the degrees of knee flexion.

The same hypothesis test was performed to determine whether the correlation between the sit and reach and PSLR was significant, obtaining 
a $\mathrm{p}$ value of 0.1132 . This result does not allow concluding an association between these two measurements. The hypothesis test for the correlation between the sit and reach and the left leg generated a $\mathrm{p}$ value of 0.0567 , which is significant at $10 \%$. This negative correlation indicates that a lower value should be expected for the left leg elevation variable when the sit and reach results are higher.

\section{Discussion}

As previously stated, flexibility is an important conditional physical quality for adequate movement and performance in sports. However, its development requires adequate strategies according to the person or athlete's requirements. Therefore, correct measurement and evaluation are fundamental $(1,9)$. This research's objective was to estimate the relationship among the results of the sit and reach test, the Schober test, and the passive straight leg raise test in pentathletes from ESMIC in Bogotá, Colombia.

The results obtained during the Schober test showed that the sample of pentathletes has lumbar spine extension movement limitations. These limitations may be associated with shortening of the trunk's posterior muscular chain, which, under normal conditions, maintains correct crown-rump positioning and functioning, following Busquet's three laws of the body: equilibrium, economy, and comfort (12). Furthermore, when considering tensegrity, shortening of this chain can directly affect the muscle chains' functioning in the lower limbs, involving the ischiotibial group that functions as rear support when the rear trunk chain attempts to stabilize the pelvis during the bipedal position (12). Tensegrity explains why one group of muscle chains affects another group of distant chains. The body is a closed chamber with a set of forces seeking balance within the body structure. Tensegrity refers to a self-balancing system composed of a continuous set of information-transmitting cables that resist the force of tension (muscles, tendons, fascia, and ligaments) and are supported by a set of struts or bars (bones) (18). 
Although in vitro studies have shown continuity between fascia and muscles anatomically located away from each other, there is lack of literature on the in vivo behavior of these connections (19). By applying tensegrity on a large scale outside of tissue samples in laboratories, the explanation of tensegrity in practice - shown in recent studies - has provided evidence of great advances in postural alterations affected by structurally distant origins, including alterations in the postural alignments of the lower back due to hamstring injuries, as shown in a study of 34 rugby players compared to a control group (20).

In the present study, the ischiotibial elasticity test showed that the pentathletes present moderate-to-severe shortening, a sign of a mechanical dysfunction associated with the lower limbs' flexing chain, which may trigger forced postural changes to compensate for the antagonistic chain's (extension muscle chain) mechanical disadvantage. Li indicates that stretching the hamstring muscles can affect movement during forward-bending, perceiving the agonist-antagonist relationship supported by tensegrity in the human body chamber (21).

The sit and reach test results corroborate the data obtained in the previous measurements, demonstrating that the sample presents a decrease in overall flexibility at the global lumbar and hamstring levels, given that the participants were unable to perform maximum lumbar flexion with knee extensions. A recent study has demonstrated the direct relationship between lumbar and hamstring function. The study, which involved 30 subjects with clinically diagnosed lumbar pain, showed a significant decrease in the hamstring muscles' length with no alteration to the pelvic tilt, demonstrating compensation within the body chamber by force compensation without significant postural alterations (22). Returning to the concept of tensegrity, it can be argued that the deficit in the sit and reach test results from myofascial dysfunctions that together limit the individuals' adequate selection, execution, and maintenance of complex postures, typical of their sporting gesture. Thus, they are forced to develop compensatory movements at the expense of excess energy consumption to meet the sporting demand and compensate for the stress balance (23). 
In summary, it has been shown that flexibility is not only dependent on the musculoskeletal system, it also depends on the surrounding tissues, like fascia, tendons, and ligaments, that form a holistic system affecting posture or movement in the human body (the closed chamber composed of compression and tension forces) (24).

\section{Conclusion}

As a conditional physical quality, flexibility is critical for movement and adopting and maintaining complex postures during sports practice. Therefore, it must be measured with quantitative and valid parameters that truly depict a real panorama of the athlete's current condition to propose therapeutic alternatives to obtain and develop standard flexibility parameters.

Based on the sample measured in this study, no relationship exists among the different flexibility tests, except for the sit and reach test and the left leg flexibility, which had a negative correlation. However, considering the human body as a tensegrity system, characterization of its flexibility requires complementary measurements to analyze and justify the dysfunctions that may occur in sports practice.

\section{References}

1. Johnson AW, Mitchell UH, Meek K, Feland JB. Hamstring flexibility increases the same with 3 or 9 repetitions of stretching held for a total time of 90 s. Phys Ther Sport. 2014;15(2):101-5.

2. Yuktasir B, Kaya F. Investigation into the long-term effects of static and PNF stretching exercises on range of motion and jump performance. J Bodyw Mov Ther. 2009;13(1):11-21.

3. McHugh MP, Cosgrave $\mathrm{CH}$. To stretch or not to stretch: the role of stretching in injury prevention and performance. Scand J Med Sci Sports [Internet]. 2009; available in: http://doi.wiley.com/10.1111/j.1600-0838.2009.01058.x

4. Alikhajeh Y, Rahimi NM, Fazeli K, Fazeli H. The Effect of Different Warm Up Stretch Protocols on 20-m Sprint Performance in Trained Soccer Players. Procedia - Soc Behav Sci. 2012;46:2210-4. 
5. Weldon SM, Hill RH. The efficacy of stretching for prevention of exercise-related injury: a systematic review of the literature. Man Ther. 2003;8(3):141-50.

6. Cronin J, Nash M, Whatman C. The acute effects of hamstring stretching and vibration on dynamic knee joint range of motion and jump performance. Phys Ther Sport. 2008;9(2):89-96.

7. Rosario JL, Foletto Á. Comparative study of stretching modalities in healthy women: Heating and application time. J Bodyw Mov Ther. 2015;19(1):3-7.

8. Ayala F, Sainz de Baranda P, De Ste Croix M, Santonja F. Comparison of active stretching technique in males with normal and limited hamstring flexibility. Phys Ther Sport. 2013;14(2):98-104.

9. Miñarro PAL, Andújar PS de B, García PLR, Toro EO. A comparison of the spine posture among several sit-and-reach test protocols. J Sci Med Sport. 2007;10(6):456-62.

10. F. Ayala, P. Sainz de Baranda, M. de Ste Croix y F. Santonja. Fiabilidad y validez de las pruebas sit-and-reach: revisión sistemática. Rev Andal Med Deporte. 2012;5(2):57-66.

11. Mayorga-Vega D, Merino-Marban R, Viciana J. Criterion-Related Validity of Sit-andReach Tests for Estimating Hamstring and Lumbar Extensibility: a Meta-Analysis. J Sports Sci Med. 2014;13(1):1-14.

12. Busquet L. Las cadenas musculares. Barcelona: Paidotribo; 2005.

13. Ferraz Pazzinatto M, Valdir Briani R, Bitencourt Oliveira C, Oliveira, Silva D. Testes clínicos para avaliação da coluna lombar e articulação sacroilíaca: revisão de literatura. ConScientiae Saúde. 2014;13(4):650-6.

14. Luque Suárez A, Fuente Hervías MT, Barón López FJ, Labajos Manzanares MT. Relación entre el test de elevación de pierna recta y el test ángulo poplíteo en la medición de la extensibilidad isquiosural. Fisioterapia. 2010;32(6):256-63.

15. Hernández Sampieri R, Fernández Collado C, Baptista Lucio P. Metodología de la investigación. 5a ed. México, D.F: McGraw-Hill; 2010. 613 p.

16. Resolución No. 8430 del 4 de Octubre de 1993 - Invima - Instituto Nacional de Vigilancia de Medicamentos y Alimentos [Internet]. [cited 17 April 2019]. Available in: https://www.invima.gov.co/resoluciones-medicamentos/2977-resolucion-no-8430-del-4-de-octubre-de-1993.html

17. Brugué JC. Guía Investigación Clínica 2013: Aspectos éticos y jurídicos a tener en cuenta en estudios clínicos en fase II y III. Documenta Universitaria; 2012. 101 p.

18. Cai J, Wang X, Yang R, Feng J. Mechanical behavior of tensegrity structures with Highmode imperfections. Mech Res Commun. 2018;94:58-63.

19. Joshi DG, Balthillaya G, Prabhu A. Effect of remote myofascial release on hamstring flexibility in asymptomatic individuals - A randomized clinical trial. J Bodyw Mov Ther. 2018;22(3):832-7.

20. Hennessey L, Watson AW. Flexibility and posture assessment in relation to hamstring injury. Br J Sports Med.1993;27(4):243-6. 
21. Li Y, McClure PW, Pratt N. The Effect of Hamstring Muscle Stretching on Standing Posture and on Lumbar and Hip Motions During Forward Bending. Phys Ther. 1996;76(8):836-45.

22. Fasuyi FO, Fabunmi AA, Adegoke BOA. Hamstring muscle length and pelvic tilt range among individuals with and without low back pain. J Bodyw Mov Ther. 2017;21(2):246-50.

23. Carreiro J. Posture, balance and movement. In: An Osteopathic Approach to Children [Internet]. Elsevier; 2009 [cited 4 May 2019]. p. 147-67. Available in: https://linkinghub.elsevier.com/retrieve/pii/B9780443067389000095

24. DellaGrotte J, Ridi R, Landi M, Stephens J. Postural improvement using core integration to lengthen myofascia. J Bodyw Mov Ther.2008;12(3):231-45.

25. Hohenschurz-Schmidt DJ, Esteves JE, Thomson OP. Tensegrity and manual therapy practice: a qualitative study. Int J Osteopath Med. 2016;21:5-18. 